\title{
Can your partner influence your physical activity? The role of social support provided by partners
}

\author{
O parceiro influencia sua atividade física? O papel do apoio social fornecido \\ pelo cônjuge
}

\section{AUTHOR'S \\ Rodrigo Wiltgen Ferreira ${ }^{1}$ (D) \\ Marlos Rodrigues Domingues ${ }^{1}$ \\ 1 Universidade Federal de Pelotas, Escola Superior de Educação Física, Programa de Pós-Graduação em Educação Física, Pelotas, Rio Grande do Sul, Brasil.}

\section{CORRESPONDING}

Rodrigo Wiltgen Ferreira

wiltgenrodrigo@gmail.com

Endereço: Escola Superior de Educação Física - UFPel, Rua Luís de Camões, 625 - Três Vendas, Pelotas, Rio Grande do Sul, Brasil. ZIP CODE: 96055-630.

DOI

$10.12820 /$ rbafs.26e0195

\section{(cc) BY}

This work is licensed under a Creative Commons Attribution 4.0 International License.

\begin{abstract}
The study aims to evaluate the association between social support from partners (SSP) and physical activity (PA) levels. A cross-sectional study conducted in 26 gyms $(\mathrm{n}=390)$ from Pelotas, Rio Grande do Sul, Brazil. Methods: PA was measured using questions about frequency/duration of PA performed at the gym and elsewhere and analyzed as numerical and dichotomized (median). SSP was measured using a validated questionnaire and analyzed in quartiles. Respectively, Linear and Poisson regression were used to assess the associations. SSP was associated with PA in both analyses. Persons belonging to the highest SSP quartile performed 66.1 (95\%CI: 11.1 - 121.0) more minutes of PA and had 1.37 (95\%CI: 1.01 - 1.85) higher probability to perform more than $300 \mathrm{~min} /$ week of PA than those from the lowest SSP quartile. SSP was associated with PA, researchers must consider the potential of SSP when targeting PA behavioral changes.

Keywords: Motor activity; Spouses; Relationship status; Social determinants of health; Psychological theory.

\section{RESUMO}

O estudo objetiva avaliar a associação entre apoio social do cônjuge (ASC) e o niveis de atividade física $(A F)$. Estudo transversal realizado em 26 academias $(n=390)$ de Pelotas, Rio Grande do Sul, Brasil. A AF foi medida usando perguntas sobre frequência e duração de AF realizadas na academia e em outros locais, a mesma foi analisada como desfecho numérico e dicotomizado (mediana). O ASC foi medido utilizando um questionário validado e analisado em quartis. Respectivamente, regressóes Linear e de Poisson foram utilizadas para avaliar as associaçôes entre os desfechos e as exposiçôes. Pessoas pertencentes ao quartil mais alto de ASC realizaram 66,1 (IC95\%: 11,1 - 121,0) mais minutos de AF e tiveram 1,37 (IC95\%: 1,01 $1,85)$ maior probabilidade de realizar mais de $300 \mathrm{~min} / \mathrm{semana} A F$ do que os do quartil de ASC mais baixo. O ASC está diretamente associado com maiores níveis de AF, pesquisadores devem considerar o potencial do $A S C$ ao direcionar as mudanças comportamentais do $A F$.
\end{abstract}

Palavras-chave: Atividade física; Cônjuges; Status de relacionamento; Determinantes sociais da saúde; Teoria psicológica.

\section{Introduction}

Physical activity (PA) is a key strategy to a healthier population. Evidence shows that $31.1 \%$ of the global adult population is physically inactive ${ }^{1}$. Even populations that engage physical activities in private services, like gyms and sports clubs, normally drop-out the behavior before three months of the beginning ${ }^{2}$, only $4 \%$ continues the practice during 12 months. Studies focusing on the potential factors that influence PA behaviors are needed to help identifying new strategies to improve population PA levels ${ }^{3}$.

Theory-based studies may help to understand how/ why some people begin exercising and give up shortly after, while others remain active ${ }^{4}$. Literature shows that the Social Cognitive Theory is the most used in PA studies. Nevertheless, when the social cognitive theory constructs are analyzed, there is clearly disparity in the number of constructs measured in the literature ${ }^{5}$. Usually, studies do not integrate all the constructs together in their analysis, fact that do not clearly shows what are the real effect of individual (self-efficacy, self-regulation) and/or social factors (social support) on the physical activity levels ${ }^{6,7}$

Evidence indicates that support of others can help people engage new health behaviors, but the literature has shown inconsistent results on the association between PA and social support of others ${ }^{8,9}$. Initial evidence shows that partner-involved (specially spouses) 
interventions can improve PA levels ${ }^{10}$. Couple characteristics, such as relationship quality, partnership, physical activity preferences and others, can be confounders of this association, influencing the effect of supportive behaviors provided each other's ${ }^{10,11}$. Thus, it remains necessary to understand how the individuals can influence partners to improve their PA levels.

This study aims to evaluate the association between social support provided by partners (SSP) and PA levels of adults enrolled in PA programs.

\section{Methods}

A cross-sectional survey with a representative sample of regular gym attendees was conducted from October 2015 to January 2016 in Pelotas, Rio Grande do Sul, Brazil, a medium-sized city in southern Brazil. Each subject was interviewed during his/her training. A team of trained interviewers was responsible for data collection. Key-questions were administered a few days later in $10 \%$ of the sample for quality control.

The sample size calculation was based on estimated prevalence of 35\% for SSP for PA, based on previous Brazilian populational studies ${ }^{12-14}$. A 5-percent point margin of error was adopted. A statistical power of $80 \%$ for the association between PA and SSP was considered, resulting in 350 individuals. After that, 10\% was added to the sample for confounding control, resulting in 385 individuals.

Multistage sampling was used. Firstly, a list of all gyms was obtained from a previous census study conducted in $2012^{15}$. Then, the list was updated using new registrations from the National Council of Physical Education, resulting in a total of 187 gyms. A random sample was obtained to determine which gyms would be invited to participate. A total of 26 gyms were invited to participate. At each gym, 15 subjects should be interviewed. A gender quota was fixed (a minimum of $30 \%$ or 4 individuals of the opposite sex) and shift hours $(33 \%$ or 5 individuals during each shift - morning/afternoon/evening) to establish a better sample distribution. This strategy resulted in a sample of 390 individuals. The inclusion criteria were age $\geq 18$ years and being in a relationship for at least 3 months. Individuals with less than 1 month of PA engagement were excluded from the sample.

The study's questionnaire was developed with a mix of questions, originals for this survey and previous validated. PA was measured with two questions assessing activities at the gym and elsewhere: 1- "Typically, how many days a week and for how long do you attend the gym?" 2- "In addition to coming to the gym, do you practice other physical activity regularly in your free time?". For both questions, weekly frequency and duration of the PA sessions were asked. A total score of regular weekly PA minutes was obtained by multiplying frequency and duration. Age was measured in numerical scale, and subsequently categorized considering the best distribution of individuals. Household income was obtained adding the income received in the previous month by any person who lived in the same house of the participant, and after was categorized into quintiles. Body Mass Index was obtained by self-reported weight, height and categorized following international recommendations.

The independent variables 'relationship satisfaction', 'self-regulation', 'self-efficacy' and 'social support' were measured using validated questionnaires. Relationship satisfaction was assessed using the Relationship Assessment Scale-RAS created by Hendrick ${ }^{16}$ and validated in Portuguese by Berti and collegues ${ }^{17}$, presenting a good internal consistency (Cronbach's $\alpha$ $=0.85)$. Self-regulation was assessed using the Exercise Goal-Setting Scale and the Exercise Planning and Scheduling Scale developed by Rovniak and collegues $^{18}$ (Cronbach's $\alpha=0.89$ and $0.87 / \mathrm{r}_{\text {test-retest }}=0.87$ and 0.89 , respectively). Self-efficacy was assessed using the Self-Efficacy and Exercise Scale developed by Sallis and collegues ${ }^{19}$ (Cronbach's $\alpha=0.84$ / rtest-retest $=0.68)$. Self-regulation and self-efficacy scales were translated into Portuguese and back-translated into English to guarantee the agreement with original questions. An English native-speaker researcher evaluated the back-to-back final version of each scale.

SSP was assessed using an adaptation of the Social Support Scale for Physical Activity developed and validated by Reis and colleagues ${ }^{20}$ for Brazilian adults. Because our sample was already physically active, we had to adapt some questions from the original scale. Originally, the scale measures social support from family and friends, but we only consider the partner as a source of support. In addition, the original scale measures social support for walking and moderate-to-vigorous PA, for this study we considered social support for PA at the gym and elsewhere. Lastly, the original social support indicators were maintained (encouragement/ joint practice/invitation) and three new social support indicators were added to the scale (praise to be physically active/financial incentives - gifts and payments/ 
helping with daily tasks). The original response options were kept: never, sometimes or always.

Independent variables included sex (male/female), age (up to 24 / 25-29 / 30-39 / 40-49 / 50-59 and older than 60 years), household income (quintiles), education (up to $8 / 9-11$ and more than 12 years), Body Mass Index (normal/overweight/obese), self-perceived health (poor - regular/good/very good and excellent), relationship status (dating/common-law or marriage), relationship duration (less than 4 years / 4-12 and more than 12 years), relationship satisfaction (quartiles), partner's PA engagement (yes/no), health professional PA recommendation (yes/no), self-regulation (quartiles), self-efficacy (quartiles) and social support (quartiles).

The PA outcome was treated as numerical and dichotomized based on the median (300 minutes/week). The second outcome configuration was presented as an additional form to interpret the data, because the score was the result of a PA behavior with regularity of five days per week and duration of one hour each day. Adjusted analyses were performed to test the association between PA and SSP for each outcome configuration. Linear regression was used in the crude and adjusted analysis for the numerical PA outcome. Chi-square tests and Poisson regression were used in the adjusted analysis for the dichotomized outcome.

A 5\%-significance level was adopted and a hierarchical model level was used to confounding control, as follows: $1^{\text {st }}$ level - sex, age, relationship status, relationship duration, house income, education years, partner's PA engagement and PA recommendation by a health professional; $2^{\text {nd }}$ level - Body Mass Index (BMI) and self-perceived health; $3^{\text {rd }}$ level - relationship satisfaction; $4^{\text {th }}$ level - self-regulation, self-efficacy; $5^{\text {th }}$ level social support.

Our protocol was approved by the Federal University of Pelotas Superior Physical Education School Ethics and Research Committee (CAAE: 47861415 .1.0000.5313/1.207.922). All participants signed informed consent forms.

\section{Results}

Four hundred and sixty-five individuals were invited to take part in the study. The refusal rate was $16.1 \%$ (75 individuals - 41 men, 34 women). The sample characteristics, uninterrupted months and weekly minutes performing PA are presented in Table 1. The sample was predominantly composed by young adults $(<39$ years) females, highly educated, married, with an active
Table 1 - Sample description, minutes of physical activity per week and uninterrupted physical activity among regular gym attendees from Pelotas, Rio Grande do Sul, Brazil, n = 390, 2016.

\begin{tabular}{|c|c|c|c|}
\hline \multirow{3}{*}{ Characteristics } & \multirow{3}{*}{$\%$} & \multicolumn{2}{|c|}{ Physical activity } \\
\hline & & $\begin{array}{c}\text { Months } \\
\text { uninterrupted }\end{array}$ & $\begin{array}{l}\text { Minutes per } \\
\text { week }\end{array}$ \\
\hline & & Mean $( \pm \mathrm{SD})$ & Mean $( \pm \mathrm{SD})$ \\
\hline \multicolumn{4}{|l|}{ Sex } \\
\hline Male & 47.9 & $29(56)$ & $378(211)$ \\
\hline Female & 52.1 & $18(36)$ & $302(148)$ \\
\hline \multicolumn{4}{|l|}{ Age (years) } \\
\hline up to 24 & 20.5 & $18(31)$ & $340(162)$ \\
\hline $25-29$ & 21.5 & $17(24)$ & 327 (191) \\
\hline $30-39$ & 23.6 & $24(47)$ & $356(209)$ \\
\hline $40-49$ & 14.4 & $33(74)$ & $380(190)$ \\
\hline $50-59$ & 11.8 & $27(42)$ & $287(159)$ \\
\hline 60 or older & 8.2 & $33(65)$ & $313(165)$ \\
\hline \multicolumn{4}{|c|}{ Household income (quintiles) } \\
\hline 1 (lowest) & 20.1 & $14(20)$ & $363(155)$ \\
\hline 2 & 22.8 & $20(42)$ & $358(180)$ \\
\hline 3 & 19.0 & $23(60)$ & $328(196)$ \\
\hline 4 & 20.9 & $33(59)$ & $327(205)$ \\
\hline 5 (highest) & 17.2 & $28(44)$ & $310(193)$ \\
\hline \multicolumn{4}{|l|}{ Education (years) } \\
\hline up to 8 & 4.1 & $13(18)$ & $417(191)$ \\
\hline $9-11$ & 49.7 & $23(55)$ & $371(201)$ \\
\hline 12 or more & 46.2 & $25(38)$ & $296(156)$ \\
\hline \multicolumn{4}{|l|}{ BMI } \\
\hline Normal & 42.8 & $21(40)$ & $301(166)$ \\
\hline Overweight & 41.0 & $29(58)$ & $372(208)$ \\
\hline Obesity & 16.2 & $14(24)$ & $354(153)$ \\
\hline \multicolumn{4}{|c|}{ Self-perceived health } \\
\hline Poor or Regular & 12.8 & $18(52)$ & $328(169)$ \\
\hline Good & 39.3 & $15(24)$ & $311(167)$ \\
\hline Very good & 29.6 & $29(53)$ & $330(172)$ \\
\hline Excellent & 18.3 & $36(64)$ & $425(228)$ \\
\hline \multicolumn{4}{|l|}{ Relationship status } \\
\hline Dating & 37.4 & $22(38)$ & 357 (192) \\
\hline Common-law & 14.4 & $22(50)$ & $330(225)$ \\
\hline Marriage & 48.2 & $24(52)$ & $326(165)$ \\
\hline \multicolumn{4}{|c|}{ Relationship duration (years) } \\
\hline less than 4 & 35.1 & $22(43)$ & $339(201)$ \\
\hline $4-12$ & 31.0 & $19(31)$ & $354(179)$ \\
\hline more than 12 & 33.9 & $30(60)$ & $323(172)$ \\
\hline \multicolumn{4}{|c|}{ Relationship satisfaction (quartiles) } \\
\hline 1 (lowest) & 31.5 & $21(43)$ & $363(220)$ \\
\hline 2 & 19.3 & $20(27)$ & $329(133)$ \\
\hline 3 & 24.2 & $19(32)$ & $305(152)$ \\
\hline 4 (highest) & 25.0 & $30(62)$ & 338 (191) \\
\hline \multicolumn{4}{|c|}{$\begin{array}{l}\text { Health professional PA } \\
\text { recommendation }\end{array}$} \\
\hline No & 68.2 & $23(41)$ & 364 (193) \\
\hline Yes & 31.8 & $25(58)$ & 285 (154) \\
\hline
\end{tabular}


To be continued Table 1 - Sample description, minutes of physical activity per week and uninterrupted physical activity among regular gym attendees from Pelotas, Rio Grande do Sul, Brazil, n = 390, 2016.

\begin{tabular}{lccc}
\hline & & \multicolumn{2}{c}{ Physical activity } \\
\cline { 3 - 4 } Characteristics & $\%$ & $\begin{array}{c}\text { Months } \\
\text { uninterrupted }\end{array}$ & $\begin{array}{c}\text { Minutes per } \\
\text { week }\end{array}$ \\
\cline { 3 - 4 } & & Mean $( \pm$ SD) & Mean $( \pm$ SD) \\
\hline Partner PA engagement & 41.8 & $22(47)$ & $362(182)$ \\
$\quad$ No & 58.2 & $24(47)$ & $322(186)$ \\
Yes & & & \\
Self-regulation (quartiles) & 25.6 & $21(36)$ & $281(147)$ \\
1 (lowest) & 24.8 & $22(42)$ & $313(148)$ \\
2 & 24.8 & $27(42)$ & $334(163)$ \\
3 & 24.8 & $25(64)$ & $427(241)$ \\
4 (highest) & & & \\
Self-efficacy (quartiles) & 29.9 & $17(29)$ & $273(133)$ \\
1 (lowest) & 24.2 & $24(57)$ & $331(164)$ \\
2 & 21.0 & $21(46)$ & $335(196)$ \\
3 & 24.9 & $30(50)$ & $415(207)$ \\
4 (highest) & &
\end{tabular}

$\mathrm{BMI}=$ body mass index $\mathrm{PA}=$ physical activity.

partner, in a relationship for less than 4 years, presenting normal BMI and with a good self-perceived health status. With respect to PA behavior, males, overweight people, with self-perceived excellent health and belonging to the highest quartiles of self-regulation and self-efficacy seem to have a stable PA behavior, performing more minutes per week and for a longer time.

Figure 1 shows the description of the SSP according to each indicator measured. The most frequent SSP indi- cators were 'incentive to practice PA at the gym', 'praise for being physically active' and "help for daily tasks'. In contrast, two out of three SSP indicators to perform PA at the gym were the less frequent indicators observed in the study (joint practice and invitation to practice).

Table 2 presents the crude and adjusted associations between PA and the sample characteristics. Women were less physically active. Time spent with PA decreased according to education level. PA increased with more self-regulation skills, self-efficacy beliefs and social support. Figure 2 shows the adjusted estimates (linear multiple regression) of physical activity minutes per week by each SSP indicator measured. Only the indicator 'encouragement for PA outside the gym' presented statistically significance.

Table 3 shows the crude and adjusted associations between the outcome 'achieving more than 300 minutes of PA per week' and the independent variables. As previously observed, women were less likely to achieve 300 minutes per week. In contrast, self-regulation skills were similar between individuals who did and did not achieve 300 minutes of PA, but self-efficacy and social support remained positively associated with the outcome.

\section{Discussion}

The results of this study show that social support provided by the conjugal partners may be a potential correlate of $\mathrm{PA}$, even controlling for individual cognitive beliefs, such as self-efficacy and self-regulation. The results agree with studies focusing on the association

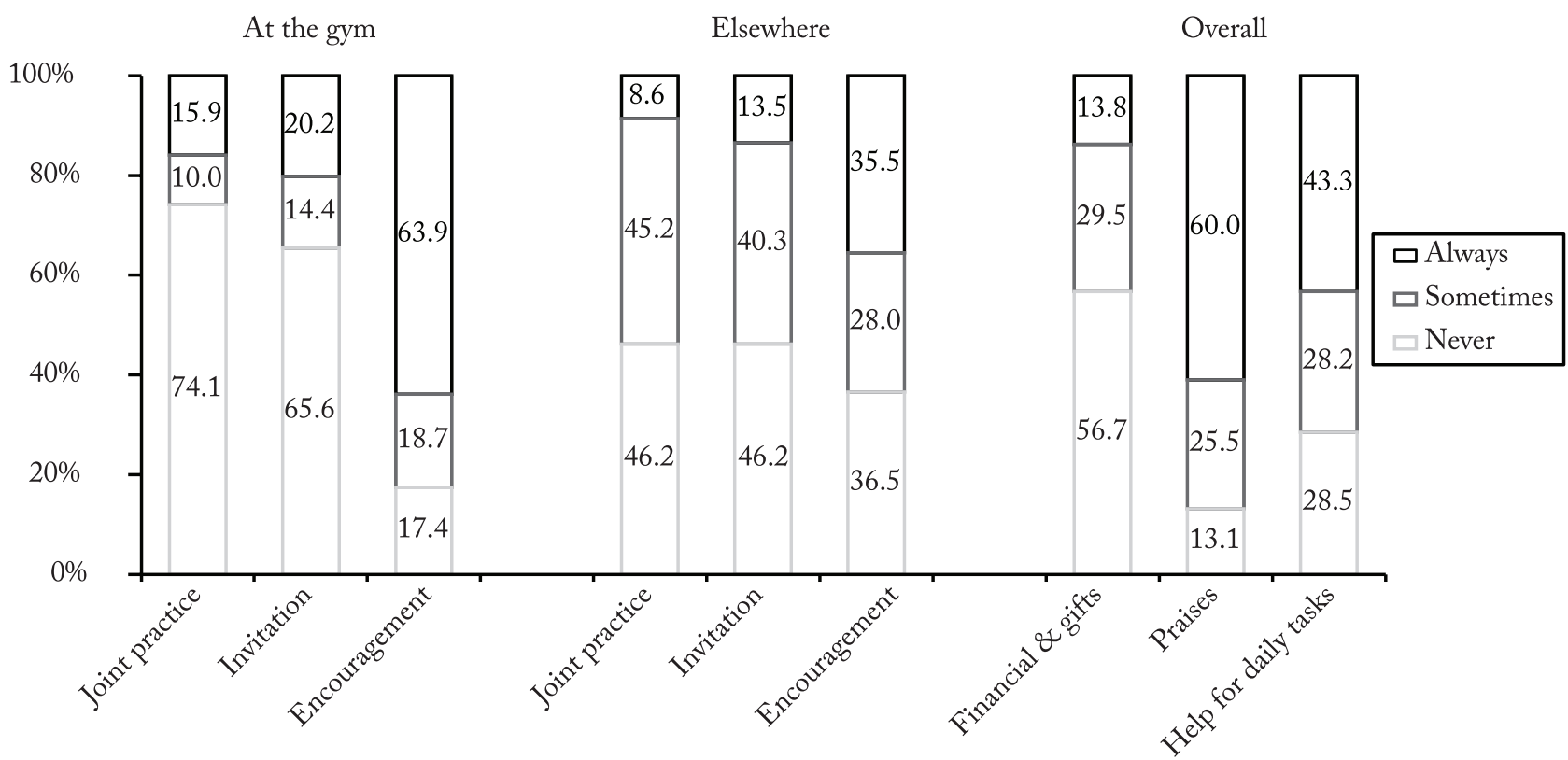

Figure 1 - Description of each partners'social support indicator measured among regular gyms attendees from Pelotas-RS Brazil, n=390, 2016. 
Table 2 - Crude and Adjusted Analysis between physical activity minutes per week and the independent variables among regular gyms attendees from Pelotas, Rio Grande do Sul, Brazil, n = 390, 2016.

\begin{tabular}{|c|c|c|c|c|c|c|}
\hline \multirow{3}{*}{ Characteristics } & \multicolumn{6}{|c|}{ Physical activity minutes per week } \\
\hline & \multicolumn{3}{|c|}{ Crude } & \multicolumn{3}{|c|}{ Adjusted } \\
\hline & $\beta$ & $(95 \% \mathrm{CI})$ & $\mathrm{p}$ & $\beta$ & $(95 \% \mathrm{CI})$ & $\mathrm{p}$ \\
\hline Sex & & & $<0.001$ & & & $<0.001$ \\
\hline Male & ref & ref & & ref & ref & \\
\hline Female & -76.0 & $(-112.2 ;-39.8)$ & & -71.1 & $(-108.0 ;-34.2)$ & \\
\hline Education (years) & & & $<0.001$ & & & $<0.001$ \\
\hline up to 8 & ref & ref & & ref & ref & \\
\hline $9-11$ & -45.5 & $(-138.3 ; 47.3)$ & & -40.0 & $(-132.6 ; 52.6)$ & \\
\hline 12 or more & -120.8 & $(-213.8 ;-27.7)$ & & -111.3 & $(-206.9 ;-15.6)$ & \\
\hline BMI & & & 0.006 & & & 0.02 \\
\hline Normal & ref & ref & & ref & ref & \\
\hline Overweight & 70.7 & $(30.9 ; 110.4)$ & & 48.4 & $(5.8 ; 91.0)$ & \\
\hline Obesity & 52.7 & $(-0.4 ; 105.9)$ & & 61.2 & $(4.6 ; 117.8)$ & \\
\hline Self-perceived health & & & 0.001 & & & 0.003 \\
\hline Poor or Regular & ref & ref & & ref & ref & \\
\hline Good & -16.7 & $(-74.8 ; 41.4)$ & & 5.8 & $(-53.0 ; 64.6)$ & \\
\hline Very good & 2.1 & $(-58.3 ; 62.5)$ & & 14.7 & $(-47.9 ; 77.2)$ & \\
\hline Excellent & 97.1 & $(31.3 ; 163.0)$ & & 96.0 & $(27.8 ; 164.1)$ & \\
\hline Health professional PA recommendation & & & $<0.001$ & & & 0.001 \\
\hline No & ref & ref & & ref & ref & \\
\hline Yes & -78.6 & $(-117.4 ;-39.7)$ & & -68.2 & $(-108.2 ;-28.1)$ & \\
\hline Self-regulation (quartiles) & & & $<0.001$ & & & 0.001 \\
\hline 1 (lowest) & ref & ref & & ref & ref & \\
\hline 2 & 32.4 & $(-18.3 ; 83.0)$ & & 11.7 & $(-36.4 ; 59.8)$ & \\
\hline 3 & 54.0 & $(3.4 ; 104.8)$ & & 32.7 & $(-15.2 ; 80.8)$ & \\
\hline 4 (highest) & 146.0 & $(95.3 ; 196.6)$ & & 86.3 & $(34.7 ; 137.8)$ & \\
\hline Self-efficacy (quartiles) & & & $<0.001$ & & & $<0.001$ \\
\hline 1 (lowest) & ref & ref & & ref & ref & \\
\hline 2 & 57.6 & $(9.5 ; 105.8)$ & & 52.7 & $(6.9 ; 98.5)$ & \\
\hline 3 & 61.9 & $(11.8 ; 112.0)$ & & 29.8 & $(-20.7 ; 80.3)$ & \\
\hline 4 (highest) & 141.8 & $(94.0 ; 189.5)$ & & 117.4 & $(67.2 ; 167.5)$ & \\
\hline Social support (quartiles) & & & 0.11 & & & 0.02 \\
\hline 1 (lowest) & ref & ref & & ref & ref & \\
\hline 2 & -8.1 & $(-56.3 ; 40.1)$ & & -0.2 & $(-46.7 ; 46.2)$ & \\
\hline 3 & 3.6 & $(-49.3 ; 56.4)$ & & 12.6 & $(-39.0 ; 64.2)$ & \\
\hline 4 (highest) & 44.8 & $(-9.4 ; 99.0)$ & & 66.1 & $(11.1 ; 121.0)$ & \\
\hline
\end{tabular}

$\mathrm{BMI}=$ body mass index; $\mathrm{PA}=$ physical activity.

Adjusted for = 1st level - sex, age, relationship status, relationship duration, house income, education years, partner's physical activity engagement and health professional physical activity recommendation. 2nd level - BMI and Self-perceived health. 3rd level - relationship satisfaction. 4th level - self-regulation, self-efficacy and social support.

between PA and SSP21,22. On the other hand, considering Brazilian studies available ${ }^{12-14}$, our study presented smaller association effects, probably due to differences in sampling and study design. Our initial hypothesis was confirmed, as SSP is associated to PA, but the effect size is smaller than for other constructs of the Social Cognitive Theory.

The SSP indicators more prevalent were those concerning verbal stimulation, as encouragement and praises. Reinforcing this fact, when analyzing individually each SSP indicator, only 'encouragement for PA practice at other sites' was statistically associated with the outcome. Some studies have described this kind of social support as the most prevalent in the adult population ${ }^{12,14}$. Another indicator highly reported in our sample was 'helping with daily tasks'. Different studies 


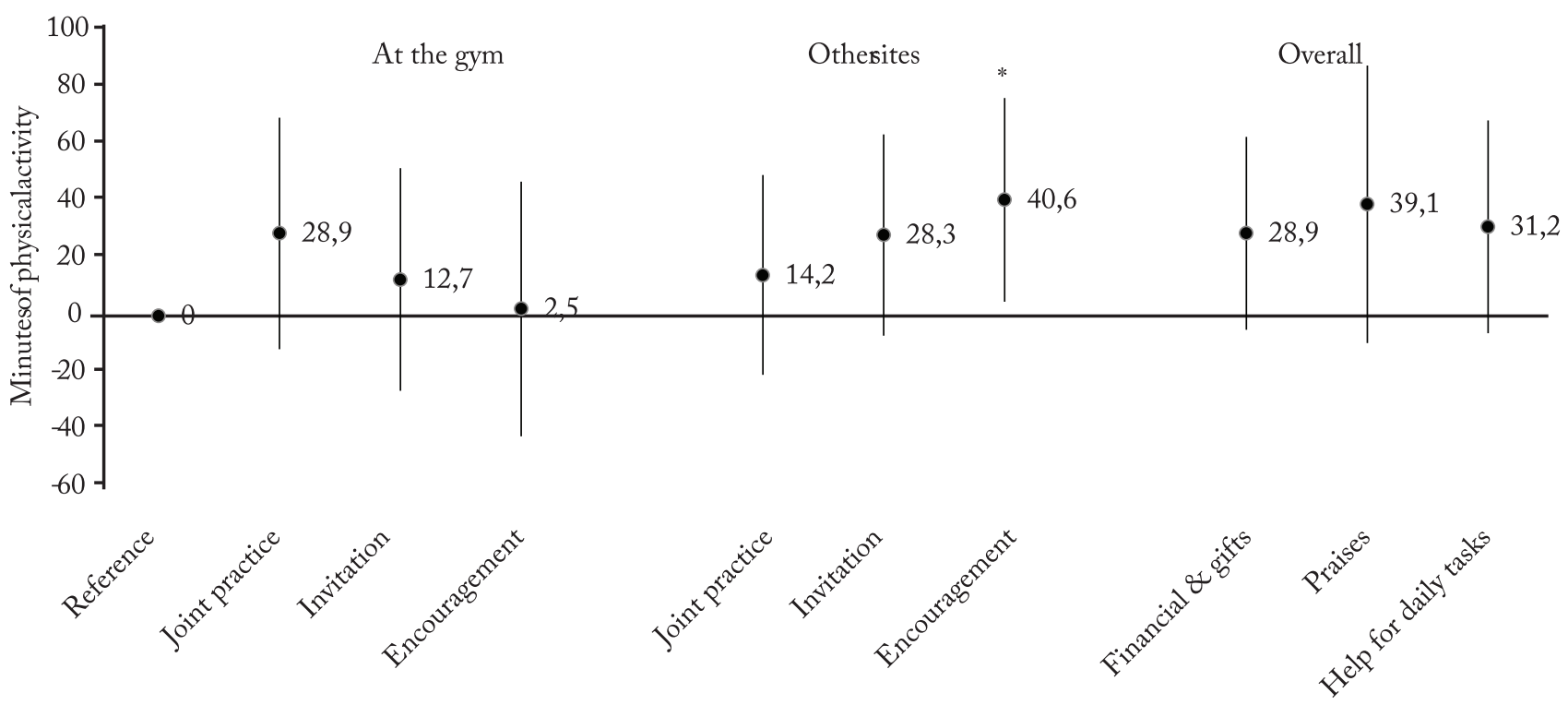

Figure 2 - Adjusted analysis between minutes of physical activity per week and each indicator of partners' social support measured.

$\mathrm{N}=390$, Pelotas-RS Brazil, 2016.

*Significant association $(\mathrm{p}=0.03)$

Adjusted for: 1st level - sex, age, relationship status, relationship duration, house income, education years, partner's physical activity engagement and health professional physical activity recommendation. 2nd level-BMI and Self-perceived health. 3rd level - relationship satisfaction. 4th level - self-regulation, self-efficacy and each social support measured

have shown that couple mutual respect, partner motivation, encouragement, persuasion and sharing daily responsibilities were identified as facilitators of PA engagement and maintenance of $\mathrm{PA}^{23-26}$. In this manner, being with a person who stimulates the adoption of behaviors, as well as implements real strategies to change some aspect that inhibits an individual to engage in PA, may be useful to turn their own beliefs and stimulates a new adoption ${ }^{10}$.

On the other hand, invitation for going to the gym, joint PA practice at the gym and financial incentives (gifts and payments) were the less reported SSP indicators. It is important to emphasize that the last two indicators were not associated with PA, but confidence intervals were very close to significance. Almost $60 \%$ of the subjects were in relationships where both were active, but apparently men and women were not engaged in the same kind of activities. Divergent exercise preferences (e.g. sites, type, frequency, intensity, goals and others) could hold back the couple to exercise togeth$\mathrm{er}^{23-25}$. This reinforces the importance of the aspects already discussed, because when the couple was engaged in the same kind of activity, the encouragement, persuasion and motivation could be facilitated ${ }^{10}$.

The total score of SSP was associated with PA in both analyses. Therefore, not necessarily social support from partner will result in increased PA levels or a change in the patterns. Carnes, Petersen and Barkley ${ }^{27}$ evaluated the influence of partnership among recreational runners and did not observe an increase in PA levels (weekly mileage, frequency or length of sessions) among those running with a family member compared to those who ran alone. On the other hand, Beverly and $\mathrm{Wray}^{24}$ demonstrated that a better communication between partners, motivation and encouragement to exercise helped type-II diabetic individuals to keep active during the an intervention.

A meta-analytic review study reported that the social support presents inconsistencies on the PA association $^{8}$. The pooled odds ratio obtained for the social support from family in prospective studies was 1.50 (95\%CI: $0.98-2.30)$, but the study-level effect ranging from small to large and from negative to positive $^{8}$. The authors emphasize that previous review studies overestimated the social support association with PA, mainly by including cross-sectional evidence ${ }^{8}$. In our opinion, this affirmation is partially correct. Our results showed a small effect of SSP on PA levels, in agreement with the meta-analytic review ${ }^{8}$, besides the differences between our study design and those included in the review. However, several cross-sectional population-based Brazilian studies reported a large effect of social support on PA levels ${ }^{12-14}$. The main reason for this discrepancy is the confounding adjustment of 
Table 3 - Crude and Adjusted Prevalence Ratios (PR) between physical activity (>300 minutes/week) and the independent variables among regular gyms attendees from Pelotas, Rio Grande do Sul, Brazil, $n=390,2016$.

\begin{tabular}{|c|c|c|c|c|c|}
\hline \multirow{3}{*}{ Characteristics } & \multicolumn{5}{|c|}{ Physical Activity > 300 minutes/week } \\
\hline & \multicolumn{2}{|c|}{ Crude } & \multicolumn{3}{|c|}{ Adjusted } \\
\hline & $\%$ & $\mathrm{p}$ & $\mathrm{PR}$ & $(95 \% \mathrm{CI})$ & $\mathrm{p}$ \\
\hline Sex & & $0.05^{\mathrm{h}}$ & & & 0.03 \\
\hline Male & 61.0 & & 1.0 & 1.0 & \\
\hline Female & 51.2 & & 0.81 & $(0.68-0.98)$ & \\
\hline Household income (quintiles) & & $<0.001^{\mathrm{t}}$ & & & 0.03 \\
\hline 1 (lowest) & 68.4 & & 1.0 & 1.0 & \\
\hline 2 & 64.0 & & 0.95 & $(0.77-1.19)$ & \\
\hline 3 & 51.4 & & 0.84 & $(0.65-1.11)$ & \\
\hline 4 & 48.1 & & 0.81 & $(0.60-1.08)$ & \\
\hline 5 (highest) & 41.5 & & 0.71 & $(0.50-1.01)$ & \\
\hline Education (years) & & $<0.001^{\mathrm{t}}$ & & & 0.002 \\
\hline up to 8 & 81.3 & & 1.0 & 1.0 & \\
\hline $9-11$ & 64.4 & & 0.88 & $(0.67-1.16)$ & \\
\hline 12 or more & 44.4 & & 0.66 & $(0.48-0.90)$ & \\
\hline BMI & & $0.004^{t}$ & & & 0.002 \\
\hline Normal & 47.3 & & 1.0 & 1.0 & \\
\hline Overweight & 61.3 & & 1.27 & $(1.02-1.58)$ & \\
\hline Obesity & 65.1 & & 1.51 & $(1.16-1.97)$ & \\
\hline Self-perceived health & & $0.02^{\mathrm{t}}$ & & & 0.04 \\
\hline Poor or Regular & 56.0 & & 1.0 & 1.0 & \\
\hline Good & 51.6 & & 1.08 & $(0.81-1.42)$ & \\
\hline Very good & 49.6 & & 1.00 & $(0.74-1.35)$ & \\
\hline Excellent & 76.1 & & 1.38 & $(1.04-1.84)$ & \\
\hline Health professional PA recommendation & & $<0.001^{\mathrm{h}}$ & & & 0.007 \\
\hline No & 62.0 & & 1.0 & 1.0 & \\
\hline Yes & 42.7 & & 0.72 & $(0.57-0.91)$ & \\
\hline Self-regulation (quartiles) & & $0.001^{\mathrm{t}}$ & & & 0.28 \\
\hline 1 (lowest) & 44.9 & & 1.0 & 1.0 & \\
\hline 2 & 52.6 & & 1.02 & $(0.78-1.35)$ & \\
\hline 3 & 57.9 & & 1.14 & $(0.87-1.48)$ & \\
\hline 4 (highest) & 68.4 & & 1.13 & $(0.86-1.49)$ & \\
\hline Self-efficacy (quartiles) & & $<0.001^{\mathrm{t}}$ & & & $<0.001$ \\
\hline 1 (lowest) & 41.2 & & 1.0 & 1.0 & \\
\hline 2 & 58.7 & & 1.61 & $(1.24-2.10)$ & \\
\hline 3 & 56.3 & & 1.43 & $(1.07-1.91)$ & \\
\hline 4 (highest) & 69.5 & & 1.81 & $(1.36-2.40)$ & \\
\hline Social support (quartiles) & & $0.20^{\mathrm{t}}$ & & & 0.01 \\
\hline 1 (lowest) & 52.3 & & 1.0 & 1.0 & \\
\hline 2 & 52.9 & & 1.10 & $(0.85-1.41)$ & \\
\hline 3 & 63.1 & & 1.39 & $(1.08-1.82)$ & \\
\hline 4 (highest) & 58.4 & & 1.37 & $(1.01-1.85)$ & \\
\hline
\end{tabular}

$\mathrm{BMI}=$ body mass index; $\mathrm{PA}=$ physical activity. hHeterogeneity chi-square test tLinear tendency chi-square test. Adjusted for $=1 \mathrm{st}$ level sex, age, relationship status, relationship duration, house income, education years, partner's physical activity engagement and health professional physical activity recommendation. 2nd level - BMI and Self-perceived health. 3rd level - relationship satisfaction. 4th level - self-regulation, self-efficacy and social support.

each study. In our analysis, when the self-regulation and self-efficacy characteristics were included into the regression model, the SSP effect decreased nearly $30 \%$ (data not shown). Usually, researchers only con- 
trol the association between PA and social support for demographic and economic characteristics, excluding individual's cognitive beliefs (e.g. self-regulation and self-efficacy). In our opinion, this fact seems to be an important factor for the overestimation of the effect of social support in cross-sectional studies, which could potentially influence the conclusions of the study published by Scarapicchia and colleagues ${ }^{8}$.

Self-regulation was associated with PA levels. Experimental evidence showed that higher self-regulation skills are associated with an increase on PA levels ${ }^{28}$. Teixeira et al. ${ }^{29}$ demonstrated that the identification and integration of different regulation skills can improve individuals' PA. However, there is no association between the dichotomized PA and self-regulation. The self-regulation skills did not differ between gym attendees who exercise more than 1 hour per day/5 days per week and those who exercise less. More studies are needed to better understand this association.

The independent variable with higher effect on PA was self-efficacy. According to the Social-cognitive theory conception, the behavior change premise includes the beliefs and abilities of each person. Self-efficacy is the theory's central construct, considered the human behavior agency ${ }^{30}$. In other words, it is through the self-efficacy beliefs that a behavior change is possible. In this manner, this effect size obtained between self-efficacy on PA was expected, mainly for being associated with the persistence to exercise $e^{3,5,6}$.

Some limitations in our study must be discussed. Because our sample was already physically active, the associations between PA and the independent variables could be underestimated in comparison with population-based studies which included inactive people. PA was self-reported. However, the weekly volume of PA was similar in subjects included in the study, and direct measures (e.g. accelerometry) would not be reasonable, because the kind of PA performed by the subjects (strength training) does not result in measurable acceleration. Thus, PA would not be better evaluated even if we used accelerometers, one of the best choices for PA assessment nowadays. The cross-sectional design hinders causal inferences. Longitudinal and experimental research are needed to understand the multiple influence mechanisms of SSP on PA levels. Also, we know that some variables treated as confounding had potential mediation effects between the PA association with SSP, but our aim was to verify the direct association between these two variables, in this manner is it possible to treat mediators as confounders.

The results may be considered for practical implication, especially considering conjugal partners as strategies of interventions addressed to change PA behavior of healthy populations. Considering the SSP indicators, may be useful considered conjugal partners as influencers, in other words, behavior changes strategies can be inputed by the conjugal partner, making them models, active actors of the behavior change of the target person.

In conclusion, SSP is associated with higher PA levels. Our results demonstrate that SSP can help adults to sustain more PA minutes per week, even those individuals were already physically active. However, the effect of SSP on PA levels can be influenced by other variables, such as self-efficacy, self-regulation, expectations, partnership and others. Thus, SSP could be important, but does not seem to be the main determinant of this behavior. Researchers must consider the potential effect of SSP on the target behavior change, because, for specific populations, it may not be strong enough to affect PA levels or patterns as expected.

\section{Conflict of interest}

The authors declare no conflict of interest.

\section{Author's contributions}

Ferreira RW, conducted the study and was the leading writer. Domingues MR, supervised the study, was the co-writer and reviewed critically the final manuscript.

\section{References}

1. Hallal PC, Andersen LB, Bull FC, Guthold R, Haskell W, Ekelund U, et al. Global physical activity levels: surveillance progress, pitfalls, and prospects. Lancet. 2012;380(9838):247-57.

2. Sperandei S, Vieira MC, Reis AC. Adherence to physical activity in an unsupervised setting: Explanatory variables for high attrition rates among fitness center members. J Sci Med Sport 2016;19(11):916-20.

3. Reis RS, Salvo D, Ogilvie D, Lambert EV, Goenka S, Brownson RC, et al. Scaling up physical activity interventions worldwide: stepping up to larger and smarter approaches to get people moving. Lancet. 2016;388(10051):1337-48.

4. Prestwich A, Sniehotta FF, Whittington C, Dombrowski SU, Rogers L, Michie S. Does theory influence the effectiveness of health behavior interventions? Meta-analysis. Health Psychol. 2014;33(5):465-74.

5. Young MD, Plotnikoff RC, Collins CE, Callister R, Morgan PJ. Social cognitive theory and physical activity: a systematic review and meta-analysis. Obes Rev. 2014;15(12):983-95.

6. Beauchamp MR, Crawford KL, Jackson B. Social cognitive theory and physical activity: Mechanisms of behavior change, critique, and legacy. Psychol Sport Exerc. 2019;42:110-7. 
7. Rhodes RE, McEwan D, Rebar AL. Theories of physical activity behaviour change: A history and synthesis of approaches. Psychol Sport Exerc. 2018;42:100-9.

8. Scarapicchia TMF, Amireault S, Faulkner G, Sabiston CM. Social support and physical activity participation among healthy adults: a systematic review of prospective studies. Int Rev Sport Exerc Psychol. 2017;10(1):50-83.

9. Rhodes RE, Lubans DR, Karunamuni N, Kennedy S, Plotnikoff R. Factors associated with participation in resistance training: a systematic review. Br J Sports Med. 2017;51(20):1466-72.

10. Richards EA, Franks MM, McDonough MH, Porter K. 'Let's move:' a systematic review of spouse-involved interventions to promote physical activity. Int $\mathrm{J}$ Health Promot Educ. 2018;56(1):51-67.

11. Berli C, Stadler G, Shrout PE, Bolger N, Scholz U. Mediators of physical activity adherence: Results from an action control intervention in couples. Ann Behav Med. 2018;52(1):65-76.

12. Böhm AW, Mielke GI, da Cruz MF, Ramirez VV, Wehrmesister FC. Social Support and Leisure-time Physical Activity among the Elderly: A Population-based Study. J Phys Act Health. 2015.

13. Rech CR, Reis RS, Hino AA, Hallal PC. Personal, social and environmental correlates of physical activity in adults from Curitiba, Brazil. Prev Med. 2014;58:53-7.

14. Silva IC, Azevedo MR, Goncalves H. Leisure-time physical activity and social support among Brazilian adults.J Phys Act Health. 2013;10(6):871-79.

15. Hartwig TW, Silva MC, Reichert FF, Rombaldi AJ. Condições de saúde de trabalhadores de academias da cidade de Pelotas-RS: um estudo de base populacional. Rev Bras Ativ Fis e Saúde. 2013;17(6):500-11.

16. Hendrick SS. A Generic Measure of Relationship Satisfaction. J Marriage Fam. 1988;50(1):93-8.

17. Berti MP, Zilberman ML, Sophia EC, Gorenstein C, Pereira AP, Lorena A, et al. Validação de escalas para avaliação do amor patológico. Rev psiquiatr clín. 2011;38:135-38.

18. Rovniak LS, Anderson ES, Winett RA, Stephens RS. Social cognitive determinants of physical activity in young adults: a prospective structural equation analysis. Ann Behav Med. 2002;24(2):149-56.

19. Sallis JF, Pinski RB, Grossman RM, Patterson TL, Nader PR. The development of self-efficacy scales for healthrelated diet and exercise behaviors. Health Educ Res. 1988;3(4):283-92.
20. Reis MS, Reis RS, Hallal PC. Validity and reliability of a physical activity social support assessment scale. Rev Saude Publica. 2011;45(2):294-301.

21. Ayotte BJ, Margrett JA, Hicks-Patrick J. Physical activity in middle-aged and young-old adults: the roles of self-efficacy, barriers, outcome expectancies, self-regulatory behaviors and social support. J Health Psychol. 2010;15(2):173-85.

22. Monin JK, Levy B, Chen B, Fried T, Stahl ST, Schulz R, et al. Husbands' and Wives' Physical Activity and Depressive Symptoms: Longitudinal Findings from the Cardiovascular Health Study. Ann Behav Med. 2015;49(5):704-14.

23. Barnett I, Guell C, Ogilvie D. How do couples influence each other's physical activity behaviours in retirement? An exploratory qualitative study. BMC Public Health. 2013;13:1197.

24. Beverly EA, Wray LA. The role of collective efficacy in exercise adherence: a qualitative study of spousal support and type 2 diabetes management. Health Educ Res. 2010;25(2):211-23.

25. Hamilton K, White KM. Understanding parental physical activity: Meanings, habits, and social role influence. Psychol Sport Exerc. 2010;11:275-85.

26. Martire LM, Stephens MA, Mogle J, Schulz R, Brach J, Keefe FJ. Daily spousal influence on physical activity in knee osteoarthritis. Ann Behav Med. 2013;45(2):213-23.

27. Carnes AJ, Petersen JL, Barkley JE. Effect of Peer Influence on Exercise Behavior and Enjoyment in Recreational Runners. J Strength Cond Res. 2016;30(2):497-503.

28. Anderson-Bill ES, Winett RA, Wojcik JR. Social cognitive determinants of nutrition and physical activity among webhealth users enrolling in an online intervention: the influence of social support, self-efficacy, outcome expectations, and self-regulation. J Med Internet Res. 2011;13(1):e28.

29. Teixeira PJ, Carraca EV, Markland D, Silva MN, Ryan RM. Exercise, physical activity, and self-determination theory: a systematic review. Int J Behav Nutr Phys Act. 2012;9:78.

30. Bandura A. Health promotion by social cognitive means. Health Educ Res. 2004;31(2):143-64.

Received: $12 / 07 / 2019$ Approved: 06/04/2021 